OPEN ACCESS

Edited by:

Michael Breitenbach,

University of Salzburg, Austria

Reviewed by:

Frederique Gaits-lacovoni,

Institut national de la santé et de la

recherche médicale, France

Valentina Tosato,

International Centre for Genetic

Engineering and Biotechnology,

Italy

${ }^{*}$ Correspondence:

Rodrigo Moore-Carrasco rmoore@utalca.cl; Nelson E. Brown nbrown@utalca.cl

Specialty section: This article was submitted to Molecular and Cellular Oncology, a section of the journal

Frontiers in Oncology

Received: 12 May 2017 Accepted: 09 August 2017 Published: 28 August 2017

Citation: Valenzuela CA, Quintanilla R, Moore-Carrasco $R$ and Brown NE

(2017) The Potential Role of

Senescence As a Modulator of Platelets and Tumorigenesis.

Front. Oncol. 7:188.

doi: 10.3389/fonc.2017.00188

\section{The Potential Role of Senescence As a Modulator of Platelets and Tumorigenesis}

\author{
Claudio A. Valenzuela ${ }^{1}$, Ricardo Quintanilla', Rodrigo Moore-Carrasco ${ }^{2 *}$ and \\ Nelson E. Brown ${ }^{1 *}$ \\ ${ }^{1}$ Center for Medical Research, University of Talca Medical School, Talca, Chile, ${ }^{2}$ Faculty of Health Sciences, University \\ of Talca, Talca, Chile
}

In addition to thrombus formation, alterations in platelet function are frequently observed in cancer patients. Importantly, both thrombus and tumor formation are influenced by age, although the mechanisms through which physiological aging modulates these processes remain poorly understood. In this context, the potential effects of senescent cells on platelet function represent pathophysiological mechanisms that deserve further exploration. Cellular senescence has traditionally been viewed as a barrier to tumorigenesis. However, far from being passive bystanders, senescent cells are metabolically active and able to secrete a variety of soluble and insoluble factors. This feature, known as the senescence-associated secretory phenotype (SASP), may provide senescent cells with the capacity to modify the tissue environment and, paradoxically, promote proliferation and neoplastic transformation of neighboring cells. In fact, the SASPdependent ability of senescent cells to enhance tumorigenesis has been confirmed in cellular systems involving epithelial cells and fibroblasts, leaving open the question as to whether similar interactions can be extended to other cellular contexts. In this review, we discuss the diverse functions of platelets in tumorigenesis and suggest the possibility that senescent cells might also influence tumorigenesis through their ability to modulate the functional status of platelets through the SASP.

Keywords: cancer, fibrinolysis, platelets, senescence, thrombosis

\section{INTRODUCTION}

Platelets are key blood components that are continuously generated in the bone marrow through fragmentation of the edges of megakaryocytes (1). In addition to their canonical role in hemostasis, platelets participate in a variety of pathological processes, including chronic inflammation and cancer (2). As the incidence of both cancer and chronic inflammatory disorders rise in an agedependent manner, the influence that aging may exert on platelet function has become particularly relevant (3). So far, however, the mechanisms involved in this age-dependent modulation of platelets or other components of the hemostasis cascade remain poorly characterized. Similarly, the age-dependent factors that modulate the interaction between platelets and cancer cells are largely unknown. Based on the capacity of senescent cells to actively modify the tissue microenvironment through the secretion of pro-inflammatory mediators, herein we speculate about the existence of a functional link between cellular senescence and platelets that may help explain the increased incidence of cancer and thrombotic diseases in older individuals. 


\section{THE COMPLEX INVOLVEMENT OF PLATELETS IN CANCER}

The functional connection between cancer and platelets has been recognized since the late nineteenth century, when an association between the occurrence of certain solid tumors and the development of venous thrombosis and blood hypercoagulability was first described (4). Accordingly, defects in platelet function or reduced platelet counts have both been associated with a reduced ability of tumors to metastasize $(5,6)$. We now know that platelets may contribute to the establishment of various hallmarks of cancer, including the ability of cancer cells to sustain proliferation, to resist apoptosis and to promote angiogenesis and metastasis (1) (for an overview of the contribution of platelets to the hallmarks of cancer, see Figure 1). It is presently unclear, however, to what extent these contributions are the result of a direct action of platelets on tumor cells or, alternatively, may be part of an underlying inflammatory process inherent to many tumors. Inflammatory cells and soluble mediators of inflammation are important constituents of the tumor microenvironment. In some tumors, inflammatory conditions are present before the occurrence of malignant transformation (7). Yet in other types of tumors, the inflammatory microenvironment emerges during the process of neoplastic transformation (8). Regardless of its origin, an environment rich in inflammatory cells and growth factors is thought to promote proliferation, angiogenesis, and/or metastasis of cancer cells $(1,7)$.

Platelets participate in diverse inflammatory processes that may be associated with cancer $(9,10)$. One of the crucial
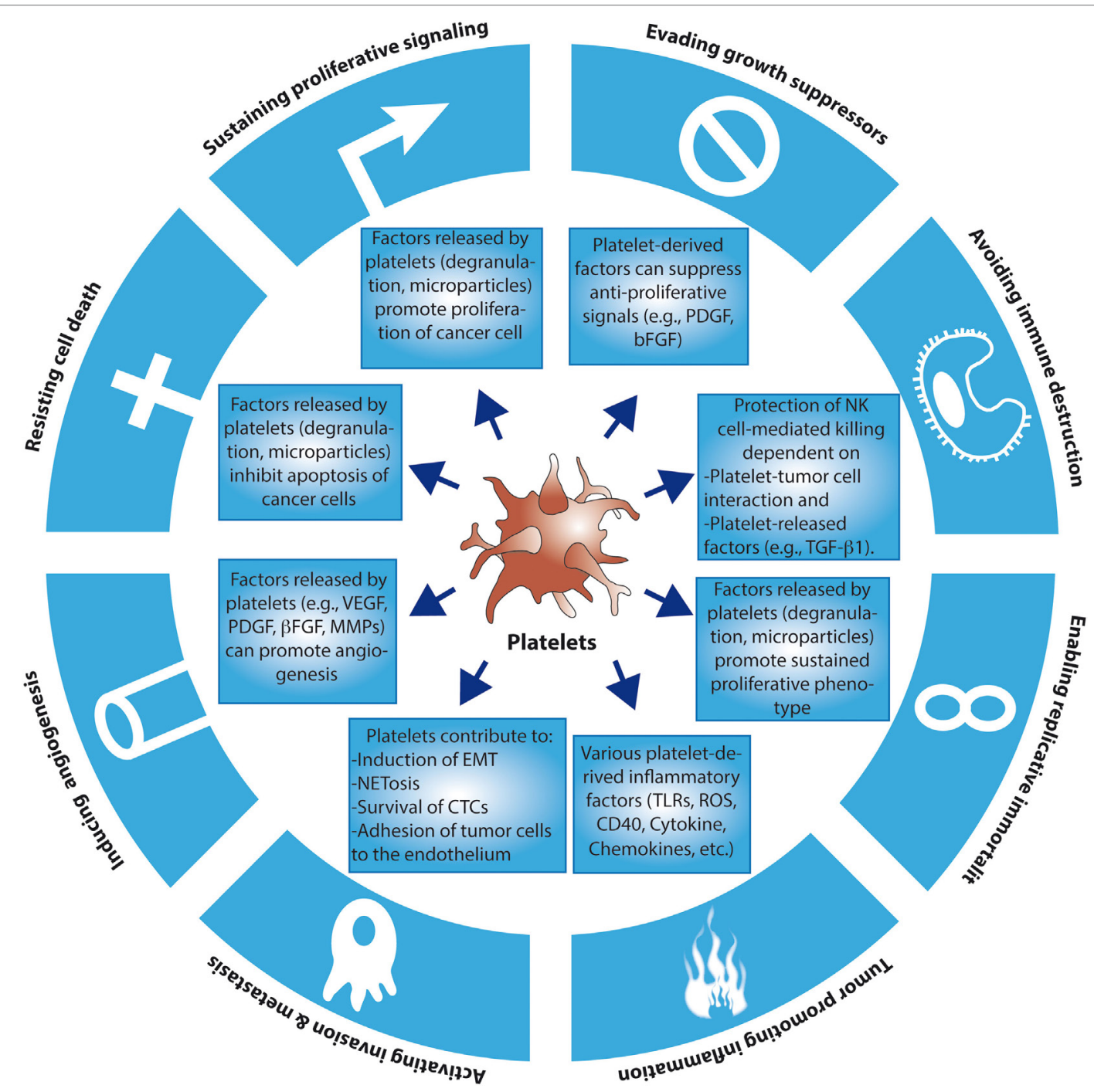

FIGURE 1 | The contributions of platelets to the hallmarks of cancer. So far, there is evidence that platelets may contribute to the emergence of several of the hallmarks of cancer through the release of soluble factors and microparticles, or through direct cancer cell-platelet interactions. For simplicity reasons, more complex and intricate mechanisms have been excluded. EMT, epithelial-mesenchymal transition; CTCs, circulating tumor cells; TLRs, toll-like receptors; ROS, reactive oxygen species; NKs, natural killers. 
inflammatory mechanisms involving platelets is NETosis. In this process, neutrophils release part of their intracellular content (chromatin, histones, enzymes, etc.) to the extracellular milieu. These components can then form a mesh that captures circulating microbes and impedes their tissue adhesion and colonization $(11,12)$. Mechanistically, granulocyte colony-stimulating factor (CSF-G) released by tumor cells is thought to increase the production of inflammatory neutrophils and promote neutrophilplatelet interaction (via P-selectin), which in turn is required to stimulate NETosis and a hyper-coagulation/pro-thrombotic state (13). More recently, NETosis has also been shown to play a role at different stages of tumorigenesis, including metastasis $(14,15)$, and the establishment of paraneoplastic syndromes leading to organ failure and thrombosis (16). Other components of innate immunity that have been associated with cancer are the inflammatory responses mediated by toll-like receptors (TLRs). Classic mediators of TLR activation are tissue damage-associated proteins, particularly members of the HMGB1 (high-mobility group box1). Whereas under normal conditions these proteins are bound to chromatin, they can be released by necrotic cells or secreted by macrophages under inflammatory or tissue damaging conditions (17). Importantly, Le-Xing et al. demonstrated that toll-like receptor 4 (TLR4), present in platelets and other cells of myeloid origin, is crucial for the interaction between tumor cells and platelets (18). Taken together, these examples illustrate the importance of platelets in the regulation of diverse protumorigenic inflammatory processes.

In addition to the general roles of platelets in inflammation, activated platelets may also participate more directly in tumor growth and metastasis. The alpha granules of platelets are the source of various trophic factors, including growth factors, chemokines, adhesion molecules, and angiogenic factors, which may promote tumor progression once they are released by activated platelets (19). In fact, the levels of many of these factors have been used as prognostic determinants in cancer patients $(20,21)$. In addition to these paracrine actions, tumor growth and metastasis also seem to depend on the ability of platelets to physically interact with tumor cells through specific integrin complexes. For example, blockade of GpIIb/IIIa-a fibrinogenbinding integrin complex that is required for platelet aggregation and binding to tumor cells-reduces the number of metastatic nodules in the lung (22). Consistent with this observation, mice deficient in $\beta 3$-integrin also display reduced metastasis (6). Altogether, these data indicate that integrin-mediated tumor cell-platelet interaction is necessary for platelet activation during metastasis (23). As mentioned above, TLR4 can also enhance tumor cell-platelet interactions, a function that is, at least in part, dependent on the release of endogenous ligand HMGB1 by tumor or damaged cells (18).

The growth factor-enriched microenvironment generated by platelet degranulation can also render tumor cells more resistant to chemotherapeutic agents (Figure 1). For example, in a group of patients with recurrent ovarian cancer, an increased number of platelets were associated with a reduction in overall survival and resistance to chemotherapy $(24,25)$. A similar phenomenon occurs in gastric cancer, where increases in both the number and volume of platelets were associated with a reduced response to chemotherapy $(26,27)$. Platelets also increase the overall survival of 5-fluorouracil- and paclitaxel-treated colon adenocarcinoma cells (28). In this case, the presence of platelets induces the expression of anti-apoptotic proteins and reduces the expression of pro-apoptotic proteins in cancer cells (28). This prosurvival effect seems to correlate with the ability of platelets to change the profile of factors secreted by cancer cells themselves, which may explain the reduced apoptotic effect of 5-fluorouracil y paclitaxel (28). Interestingly, the anti-tumorigenic effects of thrombocytopenia may also be explained by the presence of micro-hemorrhages that improve chemotherapy response (29-32). In addition to influencing anti-cancer therapy response, platelet function itself can be altered in the course of chemotherapy. For example, Kedzierska et al. described hematological alterations in patients with breast cancer before, during and after chemotherapy (33), demonstrating that the size, number, and aggregation capacities of platelets obtained from patients undergoing chemotherapy were higher compared to healthy controls (33). These changes appear to be a compensatory mechanism that hinders the correct distribution of the chemotherapeutic drugs within the tumor. Recently, Holmes et al. (34) also described changes in the secretory profile of platelets in patients with breast cancer. They observed a differential regulation in the release of angiogenic factors, especially vascular endothelial growth factor (VEGF), by platelets from individuals with cancer versus healthy individuals. Interestingly, these authors also showed that platelets from individuals undergoing chemotherapy released more angiogenic factors compared to individuals with cancer but not subjected to chemotherapy treatment (34).

Platelets may also promote distant colony formation (metastasis) by allowing the survival of tumor cells in the circulation [circulating tumor cells (CTCs)] (35). Under normal conditions, CTCs are rapidly eliminated from circulation by the host immune system or the activation of apoptosis (following lack of substrate attachment, a form of apoptosis known as anoikis). However, CTCs that become coated with platelets are protected from immune-dependent cell lysis (36). In this scenario, adhesion molecules present on the surface of activated platelets, including GpIIb/IIIa integrin, mediate the formation of heteroaggregates with tumor cells that remain shielded from immunological detection and natural killer (NK) cell-mediated lysis $(35,37)$. At least in part, this immunological tolerance may be also explained by platelet-derived secreted factors, such as TGF- $\beta 1$, that impair NK cell anti-tumor activity (38).

Platelets may also facilitate the adhesion of tumor cells to the endothelium, generating a locally protected tumor microenvironment that promotes migration of tumor cells. The establishment of this microenvironment also seems depend on granulocyte recruitment (39) and a platelet-induced increase in endothelial permeability (40). It has been shown that this effect depends on the ability of activated platelets to secrete nucleotides that act on $\mathrm{P} 2 \mathrm{Y} 2$ receptors expressed on the surface of endothelial cells. It is important to mention that platelets are also considered a major source of VEGF, an angiogenic factor that is released upon activation (41). In addition, platelet-derived TGF- $\beta 1$ enables tumor cells to undergo a process that resembles the epithelial-mesenchymal transition, thus facilitating invasion and dissemination 
(42). Finally, platelet-derived microparticles also play a role in tumor growth, migration, and metastasis (43). CTCs can increase the production of platelet-associated microparticles that promote invasiveness and metastasis (44). Among other proteins, microparticles also contain tissue factor, which is important for the generation of thrombin and the subsequent activation of protease-activated receptor-1 receptors on platelets, leading to VEGF secretion and angiogenesis (45). Taken together, the role of platelets in tumor invasion and metastasis is complex and can be explained by both direct actions on cancer cells or through collaborative effects with other cell types. So far, platelet-assisted dissemination of cancer cells has been demonstrated in the context of several human cancers, including colorectal (46), lung (47), breast (48), kidney (49), and pancreatic (50) cancers.

Tumor-derived factors leading to platelet production and activation are similarly variable and, in general, poorly understood. Several pro-inflammatory cytokines released by tumor cells, or tumor-associated stromal cells, are able to increase the number of platelets by stimulating the formation and fragmentation of megakaryocytes (51). Among the most recent findings, Stone et al. (24) reported that thrombocytosis in patients with ovarian cancer was associated with cytokine production by tumor and host tissues. In particular, tumor-derived interleukin-6 (IL-6) led to an increase in the number of activated platelets (24). Similarly, local secretion of soluble mediators by tumor cells enhances platelet activation and aggregation. For example, colorectal cancer cells induce platelet aggregation via the release of ADP and MMP-2 (52). Platelet aggregation, in turn, correlated with overexpression of GPIIb/IIIa and P-selectin in platelets, allowing the formation of tumor cell-platelet interactions $(5,52)$. Some of these mechanisms also involve the generation of thrombin (e.g., colon carcinoma cells) (53). Other mechanisms of cancerdependent platelet activation that involve cell-to-cell contact include the overexpression of podoplanin, a trans-membrane protein (also known as "aggrus") that is expressed in several tumor types (54). Podoplanin binds the c-type lectin receptor on the surface of platelets, triggering their activation $(55,56)$. Similarly, the release of cathepsin B by B16 melanoma cells can also trigger the activation of platelets (57).

\section{AGING AND PLATELETS}

So far, the role of the physiological process of aging as a modulator of platelet function, or as a factor that may influence the interaction between platelets and tumor cells, remains poorly understood (58). Early studies found that plasma concentrations and activities of various coagulation factors (fibrinogen, von Willebrand factor, factors V, VII, VIII, and IX) increase with the physiological process of aging $(3,59,60)$. Among these factors, fibrinogen is particularly relevant because it represents a primary risk factor for thrombotic disorders $(61,62)$. Interestingly, fibrinogen levels also increase in response to the pro-inflammatory cytokine IL-6. As levels of IL-6 were also strongly correlated with aging (63), these findings might suggest that high levels of fibrinogen in the elderly could be, at least in part, a reflection of an age-dependent inflammatory state. Similarly, the fibrinolytic system is also affected by aging. Thus, several studies have shown that the levels of PAI-1 (plasminogen activator inhibitor-1), a major inhibitor of fibrinolysis, increase with age $(3,64)$.

In addition to the above-mentioned hemostatic factors, platelets and endothelial cells are also affected by aging. Decrease in bleeding time (a surrogate for platelet activity) and elevation of markers of platelet activation have both been correlated with physiological aging (65). Moreover, platelets from older individuals display a greater aggregation response to ADP and collagen compared to younger individuals (66). Similarly, endothelial cells isolated from older individuals display important changes that may predispose these individuals to thrombotic disease. These changes include an age-dependent decline in endothelial production of prostacyclin and nitric oxide $(67,68)$.

Taken together, changes in virtually all aspects of hemostasis have been associated with physiological aging. As older adults often show signs of chronic inflammation, it is likely that changes in hemostasis-particularly those involving platelet function-may be part of a more general inflammatory process. So far, however, the age-dependent mechanisms involved in the modulation of hemostasis and platelet function are not completely understood. In the next sections, we advance the idea that cellular senescence might explain, at least in part, some of the hemostatic changes that lead to thrombosis and cancer.

\section{CELLULAR SENESCENCE}

Typical hallmarks of physiological aging include impaired tissue regeneration and repair, a functional impairment of progenitor cells, and alterations of the immune system (69). While the specific cellular changes associated with each one of these hallmarks will vary depending on the tissue analyzed, cellular senescence is rapidly emerging as an underlying process that may help explain some of these changes. In keeping with this idea, senescent cells accumulate in several tissues derived from aged animals $(70,71)$.

Cellular senescence was described more than 50 years ago as a process that limits the proliferation of primary human cells propagated in vitro (72). Simply stated, cellular senescence refers to a type of permanent and stable cell cycle arrest induced by numerous stimuli, including DNA damage, oxidative stress, activation of certain oncogenes, and therapeutic stress (including chemotherapy and radiotherapy). Because senescent cells cease to proliferate, cellular senescence was initially regarded as a functional equivalent of apoptosis in its ability to suppress tumor formation (73). However, recent work indicates that the physiological relevance of cellular senescence extends far beyond tumor suppression, into processes as diverse as embryonic development, wound healing, and tissue repair (74-77). Moreover, as discussed in the next section, the presence of senescent cells in tissues may actually promote the acquisition of neoplastic features by adjacent cells or otherwise foster the generation of a pro-inflammatory environment (78).

Morphologically, senescent cells appear large and "flattened" (79) and are typically positive for $\beta$-galactosidase activity at $\mathrm{pH}$ 6.0, a reflection of the high content of lysosomes in these cells $(78,80)$. Another prominent feature of senescent cells is the presence of "senescence-associated heterochromatin 
foci," which correspond to regions of chromatin condensation (heterochromatin) that appear as bright and dense foci in the nuclei of senescent cells $(81,82)$. The cell cycle exit observed in senescent cells is generally associated with a typical DNA content of G1 phase, that is, a failure to initiate DNA replication even when growth conditions are adequate. The initial transition from cycling to cell cycle arrest involves a reduction in the activity of cyclin/cyclin-dependent kinases (CDKs) complexes, leading ultimately to the activation of the p53 and pRB tumor suppressor pathways $(83,84)$. For example, the transcription factor p53 can be stabilized in response to various stressful stimuli, increasing the expression of various target genes that trigger cellular senescence or, in extreme cases, apoptosis. One of these targets, $\mathrm{p} 21^{\mathrm{Cip} 1 / \mathrm{WAF} 1}$, is a potent inhibitor of cyclin/CDK complexes. Similarly, p16 $6^{\mathrm{INK} 4 \mathrm{a}}$, another inhibitor of CDKs, is highly expressed in senescent cells $(83,85)$. The upregulation of both types of CDK inhibitors results in the inhibition of CDKs and the subsequent activation (through hypo-phosphorylation) of the pRB pathway, event that effectively blocks the G1-S transition (86) (see Figure 2).

Historically, the extent to which cellular senescence contributes to organismal aging and age-driven tissue dysfunction has been difficult to establish, in part due to the lack of markers that could specifically detect senescent cells in aging tissues (87). Nonetheless, the use of combinations of markers has provided convincing evidence that senescent cells do accumulate in aged tissues, as well as in sites of tissue injury and repair $(71,74,88)$. For example, markers of DNA damage and de-repression of the INK4/ARF locus-which encodes for the tumor suppressive proteins $\mathrm{p} 16^{\mathrm{INK} 4 \mathrm{~A}}$ and $\mathrm{p} 19^{\mathrm{ARF}}$ - increase with chronological aging. Accordingly, the levels of $\mathrm{p} 16^{\mathrm{INK} 4 \mathrm{~A}}$ correlate with the aging of numerous tissues from mice and humans $(89,90)$. Moreover, for at least some tissues (e.g., liver, skin, lung, and spleen), a good correlation between the proportion of cells with DNA damage, and the proportion of cells displaying senescence-associated $\beta$-galactosidase activity, has been found (71).

Taken together, the current evidence indicates that in addition to functioning as a barrier against tumor formation, cellular senescence is also active during embryonic development, tissue repair, and organismal aging. The involvement of cellular senescence in these physiological processes is currently thought to depend on the ability of senescent cells to produce and secrete a variety of factors that can impinge on neighboring cells and the extracellular matrix (ECM), a function that only becomes evident in the context of complex tissues. As mentioned in the following sections, these non-cell autonomous capabilities of senescent cells are also emerging as key contributors to the pathogenesis of age-related conditions, including chronic inflammation, fibrosis, and, paradoxically, cancer.

\section{THE SENESCENCE-ASSOCIATED SECRETORY PHENOTYPE (SASP)}

In addition to cell cycle arrest, the establishment of a mature senescent phenotype involves extensive metabolic reprograming, as well as the implementation of complex traits such as the

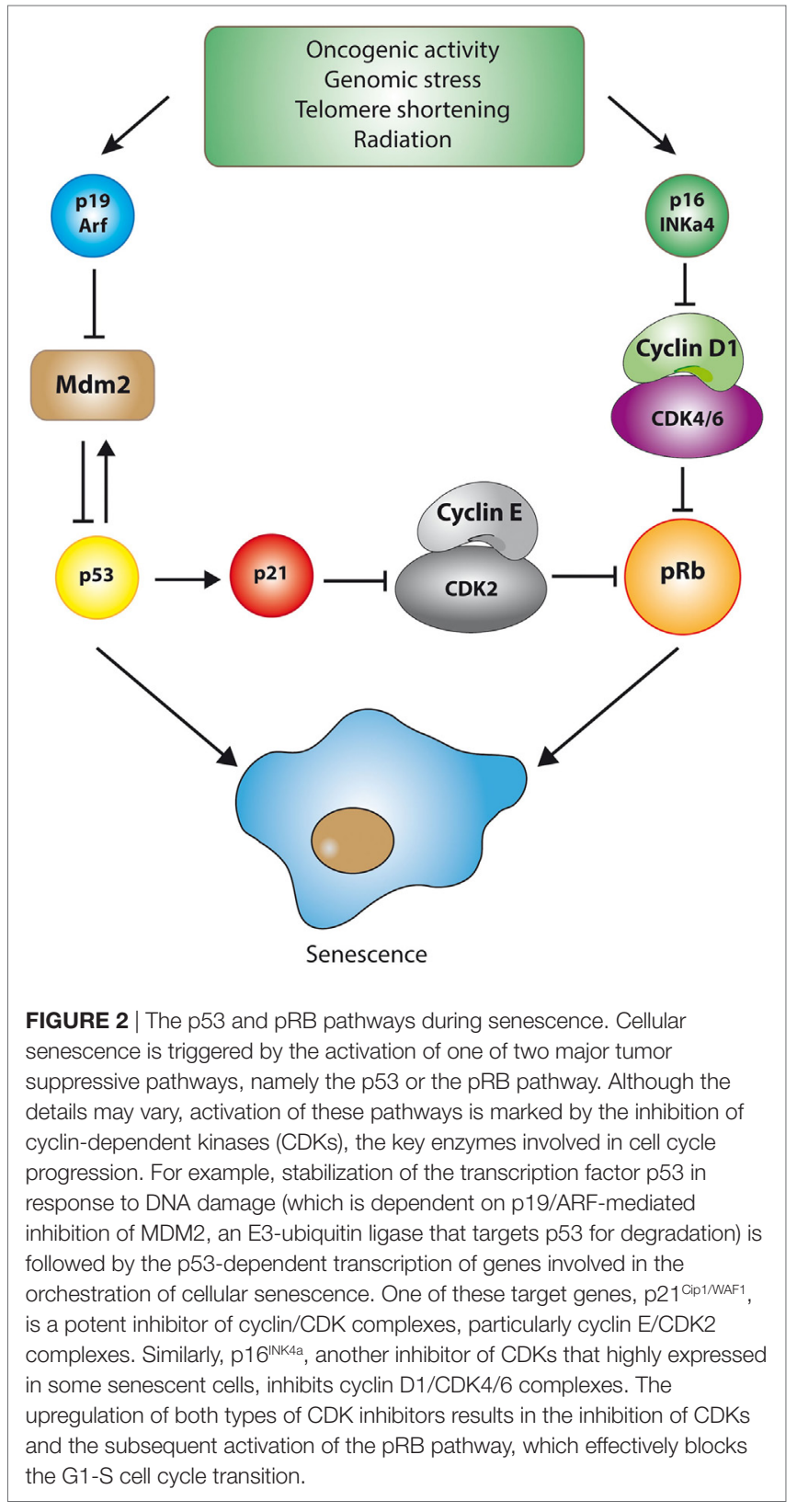

SASP $(91,92)$. The SASP refers to the almost universal capacity of senescent cells to produce and secrete a variety of soluble and insoluble factors, including extracellular proteases, cytokines, chemokines, and growth factors. This ability of senescent cells to potentially modify the tissue microenvironment (neighboring cells and the ECM) via SASP adds a further layer of complexity to the implications of cellular senescence to tissue homeostasis and disease (93-96).

A common feature of aging and age-related diseases is chronic inflammation. The term "inflamm-aging" has been coined to describe a low-grade, chronic, and systemic inflammation associated with aging and aging phenotypes in the absence of evidence of infection (97). In line with this concept, many of the factors secreted by senescent cells are also well-known 
pro-inflammatory molecules with the potential to induce chronic inflammation in certain biological contexts $(69,98)$. Indeed, early microarray analyses revealed that senescent fibroblasts display an expression profile that resembles the one displayed by fibroblasts in early stages of wound repair (99). More recently, a unique type of inflammation triggered by senescent cells, the senescence-inflammatory response, has been identified (100). Interestingly, similar to chronic inflammation produced by other mechanisms, the inflammatory "secretoma" produced by senescent cells also seems to depend on activation of the NF- $\mathrm{KB}$ and C/EBP- $\beta$ transcriptional regulators (101). Examples of conserved components of the SASP with known pro-inflammatory actions include IL-6 (102), IL-1- $\alpha$ (103) macrophage inflammatory protein, various metalloproteinases (MMP-2, -4, -1), GM-CSF, and cathepsin B $(93,104)$.

As expected, the SASP can have complex effects on tissue microenvironments. Thus, some components of the SASP can propagate or reinforce the senescent phenotype through autocrine or paracrine mechanisms, leading to further secretion and amplification of the SASP (105). In addition, SASP factors may attract immune cells, which in turn can orchestrate the elimination of senescent cells and the termination of a senescence-associated inflammatory response. Importantly, clearance of senescent cells seems to dictate the net effect of cellular senescence at the organismal level (106). While transient and limited cellular senescence can be beneficial in the context of the normal tissue remodeling that occurs during embryonic development and wound healing, chronic accumulation of senescent cellsowing to age-dependent deterioration of the innate or adaptive immunity - can have important detrimental consequences. For example, pro-inflammatory cytokines secreted by senescent cells may promote chronic inflammation and, depending on the biological context, lead to pathological conditions characterized by an excess of fibrosis (e.g., liver cirrhosis) $(74,107)$. Moreover, the SASP, particularly its inflammatory component, can accelerate tumor initiation and progression by fostering a pro-tumorigenic microenvironment $(106,108)$. Accordingly, clearance of tumor cells (or cells of the tumor stroma) undergoing genetically or drug-induced senescence leads to long-term regression and reduced recurrence of tumors in mouse models of liver and breast tumorigenesis $(107,109-113)$.

The complex heterotypic interactions in which senescent cells can participate were anticipated by early in vitro experiments showing that senescent fibroblasts can enhance proliferation and tumorigenesis of epithelial cells of various types (114-117). For example, factors secreted by senescent fibroblasts, such as amphiregulin and GRO $\alpha$, stimulate the proliferation of premalignant prostate epithelial cells $(93,114)$. Similarly, high levels of IL-6 and IL-8, also produced by senescent fibroblasts, can promote invasion of weakly malignant keratinocytes (118). Importantly, coinjection of senescent fibroblasts with either premalignant or malignant mammary epithelial cells can lead to, or accelerate, tumor formation in mice (116). Furthermore, normal human prostate epithelial cells undergoing senescence can also enhance in vivo tumorigenicity of low- or non-tumorigenic prostate cancer cells, suggesting that factors released by senescent epithelial cells can also be protumorigenic (119). It is worth mentioning that the SASP-dependent ability of senescent cells to promote tumorigenesis has been mainly reported in cellular systems involving co-cultures of epithelial cells and fibroblasts. Therefore, it remains unknown if similar interactions can be observed in other cellular contexts. Finally, it is important to emphasize that not all components of a SASP are pro-tumorigenic. Some SASP components have anti-angiogenic effects or are even able to induce apoptosis or senescence in non-senescent neighboring cells $(120,121)$.

\section{THE POTENTIAL ROLE OF THE SASP IN HEMOSTASIS}

Based on the emerging physiological and pathological processes in which the SASP might be involved, it is conceivable that senescent cells may also affect hemostasis through mechanisms that include, but are not limited to, changes in the production and functional status of platelets. As mentioned elsewhere in this review, IL-6 is one of the most prominent pro-inflammatory cytokines present in the SASP (102). Interestingly, IL- 6 has been postulated as a central mediator of age-associated inflammatory pathways (63), with serum concentrations of IL-6 increasing with age (122). Moreover, IL-6 upregulates the synthesis of hemostatic factors, such as fibrinogen, and may also directly activate platelets $(63,123)$. Thus, it is tempting to speculate that the high levels of IL- 6 (and other pro-inflammatory factors, such as IL- $1 \beta$ and TNF- $\alpha$ ) detected in aged individuals could reflect, at least in part, an increased rate of secretion of this cytokine

TABLE 1 | Senescence-associated secretory phenotype (SASP) factors with potential effect on platelets aggregation and the fibrinolytic system.

\begin{tabular}{|c|c|}
\hline SASP component & Function \\
\hline Interleukin-6 & $\begin{array}{l}\text { Upregulates the production of hepatic thrombopoetin, } \\
\text { elevating the number of platelets number (24) }\end{array}$ \\
\hline IL-11 & $\begin{array}{l}\text { Contributes to megakaryopoiesis and thus indirectly } \\
\text { to thrombopoiesis }(51,128)\end{array}$ \\
\hline PAl-1 & $\begin{array}{l}\text { Main inhibitor of tissue plasminogen activator and } \\
\text { urokinase (24), regulates the dissolution of fibrin and } \\
\text { also inhibits the degradation of the extracellular matrix } \\
\text { by reducing plasmin generation (129) }\end{array}$ \\
\hline MMP-2 & $\begin{array}{l}\text { Released by tumor cells and activated platelets } \\
\text { in vitro (130) }\end{array}$ \\
\hline GM-CSF & $\begin{array}{l}\text { Contributes to megakaryopoiesis and thus indirectly } \\
\text { to thrombopoiesis (51) }\end{array}$ \\
\hline
\end{tabular}

Fibronectin Involved in cell adhesion and migration processes, including embryogenesis, wound healing, blood coagulation, host defense, and metastasis (131)

THPO Necessary for megakaryocyte proliferation and maturation, as well as for thrombopoiesis (132)

Granulocyte colony- Cancer cell releases high levels of G-CSF primed stimulating factor neutrophils to release NETs, activating platelets (133), (G-CSF) and also contributes to megakaryopoiesis and thus indirectly to thrombopoiesis (51)

MMP1 Activates protease-activated receptor-1 (PAR-1) by cleaving the receptor and promotes platelet aggregation through PAR-1 (134) 
by senescent cells-or by other cells responding to senescent cells-in the context of a senescence-induced chronic inflammation. An age-dependent increase of pro-inflammatory factors would, in turn, contribute to platelet activation and a higher proclivity to thrombus formation. Therefore, we postulate that cellular senescence (as a result of physiological aging or secondary to therapeutic stress) might play an important role in the regulation of platelet function. By regulating the activation of platelets, senescent cells could provide yet another mechanism contributing to the higher prevalence of chronic inflammation (and cancer) in aged individuals.

While direct interaction between senescent cells and platelets remains to be experimentally confirmed, components of the SASP have already been linked to the modulation of the process of fibrinolysis via the plasminogen activation pathway $(93,124)$. Thus, increased plasma levels of PAI-1 (plasminogen activator inhibitor-1) are associated with a variety of ageassociated conditions, including thrombogenic endothelial dysfunction (93). Supporting the connection between cellular senescence and thrombogenesis, PAI-1 mRNA and protein levels are also constitutively upregulated in senescent endothelial cells (125). In addition, fibroblasts and endothelial cells isolated from elderly donors or from patients with Werner syndrome-a disease characterized by premature aging and atherosclerosis-also display elevated levels of PAI-1 (126). Taking together, these data support the existence of a close association between aging, cellular senescence, and the deterioration of the fibrinolytic system.

Finally, senescent cells also secrete insoluble proteins that are normally present in the ECM and accumulate as a consequence of chronic inflammatory processes. One prominent example is fibronectin, a component of the connective tissue that is also found on cell surfaces, plasma, and other body fluids. Importantly, it has been demonstrated that fibronectin stabilizes the hemostatic clot, controls the diameter of the fibrin fiber, and also enhances platelet adhesion (127).

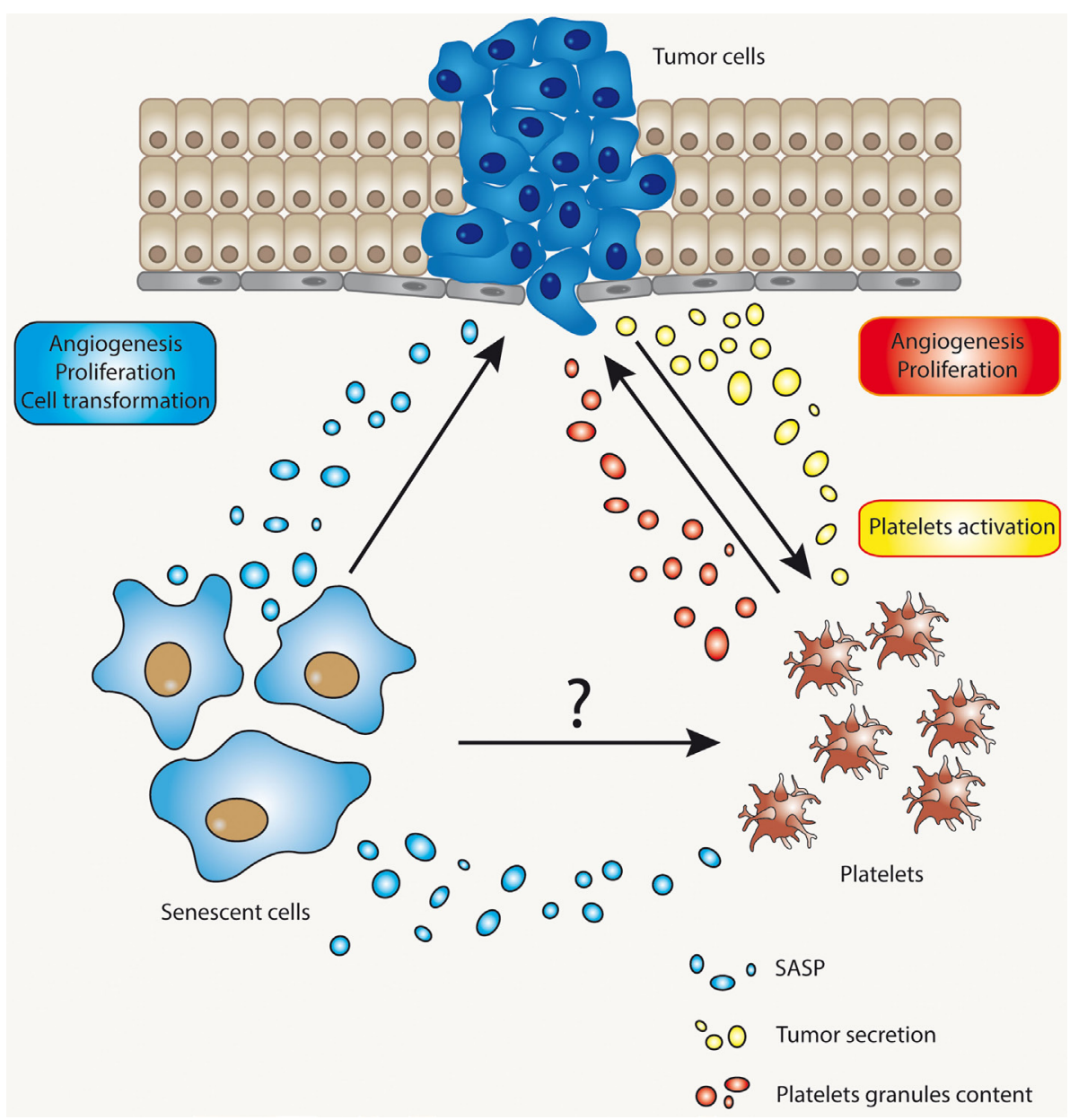

FIGURE 3 | The complex interaction between senescent cells, tumor cells, and platelets. The interaction between tumor cells and platelets is already well known. Tumor cells may affect platelet activation through several mechanisms and, reciprocally, activated platelets may release factors that impinge on proliferation and metastasis of tumor cells, or cells in the process of becoming tumorigenic. Senescent cells, on the other hand, might cause alterations in microenvironment through their ability to develop a secretory phenotype [senescence-associated secretory phenotype (SASP)]. SASP's components, for example, could alter the functional status of platelets or the process of fibrinolysis. 
Taken together, the data support a model in which SASP components could modulate various aspects of hemostasis, including the functional status of platelets. Local activation of platelets, in turn, could contribute propitiate chronic inflammation, accelerate tumor progression, and enhance thrombus formation. A selection of senescence-associated secreted factors that could modify the function or production of platelets is listed in Table 1.

\section{CONCLUDING REMARKS}

The functional interaction between cancer cells and platelets has been well established. Most of the efforts aimed to clarify these interactions have been focused on the ability of tumor cells (or tumor-associated stromal cells) to produce and secrete pro-inflammatory factors that can result in the activation of platelets. Active platelets-acting synergistically with other components of the tumor stroma-can then promote or enhance tumor progression and metastasis. Paradoxically, many of the factors secreted by tumor cells or tumor-associated inflammatory cells with a known effect on platelet activity are also produced and secreted by cells undergoing senescence, a process originally regarded as tumor suppressive. Indeed, the evidence indicates that cellular senescence may also play an active role in driving, rather than suppressing, tumor formation, a non-cell autonomous role that seems to be largely dependent on the SASP. Accordingly, factors released by senescent cells may help create a pro-tumorigenic microenvironment that enhances proliferation and migration of neighbor cells (135). Although still controversial, this model would be in line with the observation that the prevalence of most cancers increases with age.

\section{REFERENCES}

1. Franco AT, Corken A, Ware J. Platelets at the interface of thrombosis, inflammation, and cancer. Blood (2015) 126(5):582-8. doi:10.1182/blood2014-08-531582

2. Mohebali D, Kaplan D, Carlisle M, Supiano MA, Rondina MT. Alterations in platelet function during aging: clinical correlations with thromboinflammatory disease in older adults. J Am Geriatr Soc (2014) 62(3):529-35. doi:10.1111/jgs. 12700

3. Franchini M. Hemostasis and aging. Crit Rev Oncol Hematol (2006) 60(2):144-51. doi:10.1016/j.critrevonc.2006.06.004

4. Varki A. Trousseau's syndrome: multiple definitions and multiple mechanisms. Blood (2007) 110(6):1723-9. doi:10.1182/blood-2006-10-053736

5. Kim YJ, Borsig L, Varki NM, Varki A. P-selectin deficiency attenuates tumor growth and metastasis. Proc Natl Acad Sci U S A (1998) 95(16):9325-30. doi:10.1073/pnas.95.16.9325

6. Bakewell SJ, Nestor P, Prasad S, Tomasson MH, Dowland N, Mehrotra M, et al. Platelet and osteoclast beta3 integrins are critical for bone metastasis. Proc Natl Acad Sci U S A (2003) 100(24):14205-10. doi:10.1073/pnas. 2234372100

7. Mantovani A, Allavena P, Sica A, Balkwill F. Cancer-related inflammation. Nature (2008) 454(7203):436-44. doi:10.1038/nature07205

8. Crusz SM, Balkwill FR. Inflammation and cancer: advances and new agents. Nat Rev Clin Oncol (2015) 12(10):584-96. doi:10.1038/nrclinonc.2015.105

9. Jenne CN, Kubes P. Platelets in inflammation and infection. Platelets (2015) 26(4):286-92. doi:10.3109/09537104.2015.1010441

10. Thomas MR, Storey RF. The role of platelets in inflammation. Thromb Haemost (2015) 114(3):449-58. doi:10.1160/TH14-12-1067
Alterations in hemostasis involving platelet dysfunction or alterations in the process fibrinolysis are at the core of thrombogenesis (136). As with cancer, thrombogenesis is most commonly observed in older individuals, who presumably harbor a higher proportion of senescent cells in their tissues. We, therefore, postulate that cellular senescence, either as a result of normal aging or secondary to stress, could play an important role in the regulation of platelet function. Figure 3 depicts the potential relationship between senescent cells, platelets, and cells at risk of becoming tumorigenic. According to this model, senescent cells have the ability to modify the microenvironment in ways that may enhance tumorigenesis. Similarly, senescent cells might also regulate the activity of platelets, the process of fibrinolysis, or both. By regulating the activation of platelets, senescent cells may provide yet another mechanism to enhance tumorigenesis. Whether or not these circuits are relevant to tumorigenesis and/or thrombogenesis remains to be fully elucidated.

\section{AUTHOR CONTRIBUTIONS}

$\mathrm{CV}$ contributed to writing the manuscript, figures, and the final submission. RQ contributed to writing specific sections of the manuscript. RM-C and NB contributed to writing, editing, and discussing the manuscript. All authors read and approved the final manuscript.

\section{FUNDING}

This work was supported by the National Fund for Scientific \& Technological Development (FONDECYT) Grant 1140389 (NBV), and the Regional Funds for Innovation and Competiveness (FIC-R) number 30388034 (NBV).

11. Brinkmann V, Reichard U, Goosmann C, Fauler B, Uhlemann Y, Weiss DS, et al. Neutrophil extracellular traps kill bacteria. Science (2004) 303(5663):1532-5. doi:10.1126/science.1092385

12. Urban CF, Reichard U, Brinkmann V, Zychlinsky A. Neutrophil extracellular traps capture and kill Candida albicans yeast and hyphal forms. Cell Microbiol (2006) 8(4):668-76. doi:10.1111/j.1462-5822.2005. 00659.x

13. Demers M, Krause DS, Schatzberg D, Martinod K, Voorhees JR, Fuchs TA, et al. Cancers predispose neutrophils to release extracellular DNA traps that contribute to cancer-associated thrombosis. Proc Natl Acad Sci U S A (2012) 109(32):13076-81. doi:10.1073/pnas.1200419109

14. Demers M, Wong SL, Martinod K, Gallant M, Cabral JE, Wang Y, et al. Priming of neutrophils toward NETosis promotes tumor growth. Oncoimmunology (2016) 5(5):e1134073. doi:10.1080/2162402X.2015.1134073

15. Cedervall J, Zhang YY, Olsson AK. Tumor-induced NETosis as a risk factor for metastasis and organ failure. Cancer Res (2016) 76(15):4311-5. doi:10.1158/0008-5472.CAN-15-3051

16. Cedervall J, Zhang Y, Huang H, Zhang L, Femel J, Dimberg A, et al. Neutrophil extracellular traps accumulate in peripheral blood vessels and compromise organ function in tumor-bearing animals. Cancer Res (2015) 75(13):2653-62. doi:10.1158/0008-5472.CAN-14-3299

17. Andersson U, Tracey KJ. HMGB1 is a therapeutic target for sterile inflammation and infection. Annu Rev Immunol (2011) 29:139-62. doi:10.1146/ annurev-immunol-030409-101323

18. Yu LX, Yan L, Yang W, Wu FQ, Ling Y, Chen SZ, et al. Platelets promote tumour metastasis via interaction between TLR4 and tumour cell-released high-mobility group box1 protein. Nat Commun (2014) 5:5256. doi:10.1038/ Ncomms6256 
19. Tesfamariam B. Involvement of platelets in tumor cell metastasis. Pharmacol Ther (2016) 157:112-9. doi:10.1016/j.pharmthera.2015.11.005

20. Peterson JE, Zurakowski D, Italiano JE Jr, Michel LV, Connors S, Oenick M, et al. VEGF, PF4 and PDGF are elevated in platelets of colorectal cancer patients. Angiogenesis (2012) 15(2):265-73. doi:10.1007/ s10456-012-9259-z

21. Italiano JE, Richardson JL, Patel-Hett S, Battinelli E, Zaslavsky A, Short S, et al. Angiogenesis is regulated by a novel mechanism: pro- and antiangiogenic proteins are organized into separate platelet alpha granules and differentially released. Blood (2008) 111(3):1227-33. doi:10.1182/ blood-2007-09-113837

22. Amirkhosravi A, Mousa SA, Amaya M, Blaydes S, Desai H, Meyer T, et al. Inhibition of tumor cell-induced platelet aggregation and lung metastasis by the oral GpIIb/IIIa antagonist XV454. Thromb Haemost (2003) 90(3):549-54. doi:10.1160/TH03-02-0102

23. Lonsdorf AS, Kramer BF, Fahrleitner M, Schonberger T, Gnerlich S, Ring S, et al. Engagement of alphaIIbbeta3 (GPIIb/IIIa) with alphanubeta3 integrin mediates interaction of melanoma cells with platelets: a connection to hematogenous metastasis. J Biol Chem (2012) 287(3):2168-78. doi:10.1074/ jbc.M111.269811

24. Stone RL, Nick AM, McNeish IA, Balkwill F, Han HD, Bottsford-Miller J, et al. Sood paraneoplastic thrombocytosis in ovarian cancer. $N$ Engl J Med (2012) 366(7):610-8. doi:10.1056/NEJMoa1110352

25. Bottsford-Miller J, Choi H-J, Dalton HJ, Stone RL, Cho MS, Haemmerle $M$, et al. Differential platelet levels affect response to taxane-based therapy in ovarian cancer. Clin Cancer Res (2015) 21(3):602-10. doi:10.1158/1078-0432.ccr-14-0870

26. Lian L, Xia Y-Y, Zhou C, Shen X-M, Li X-L, Han S-G, et al. Mean platelet volume predicts chemotherapy response and prognosis in patients with unresectable gastric cancer. Oncol Lett (2015) 10(6):3419-24. doi:10.3892/ ol.2015.3784

27. Sun K-Y, Xu J-B, Chen S-L, Yuan Y-J, Wu H, Peng J-J, et al. Novel immunological and nutritional-based prognostic index for gastric cancer. World J Gastroenterol (2015) 21(19):5961-71. doi:10.3748/wjg.v21.i19.5961

28. Radziwon-Balicka A, Medina C, O’Driscoll L, Treumann A, Bazou D, Inkielewicz-Stepniak I, et al. Platelets increase survival of adenocarcinoma cells challenged with anticancer drugs: mechanisms and implications for chemoresistance. Br J Pharmacol (2012) 167(4):787-804. doi:10.1111/ j.1476-5381.2012.01991.x

29. Demers M, Ho-Tin-Noé B, Schatzberg D, Yang JJ, Wagner DD. Increased efficacy of breast cancer chemotherapy in thrombocytopenic mice. Cancer Res (2011) 71(5):1540-9. doi:10.1158/0008-5472.can-10-2038

30. Ho-Tin-Noe B, Goerge T, Cifuni SM, Duerschmied D, Wagner DD. Platelet granule secretion continuously prevents intratumor hemorrhage. Cancer Res (2008) 68(16):6851-8. doi:10.1158/0008-5472.CAN-08-0718

31. Ho-Tin-Noe B, Carbo C, Demers M, Cifuni SM, Goerge T, Wagner DD. Innate immune cells induce hemorrhage in tumors during thrombocytopenia. Am J Pathol (2009) 175(4):1699-708. doi:10.2353/ajpath.2009. 090460

32. Goerge T, Ho-Tin-Noe B, Carbo C, Benarafa C, Remold-O'Donnell E, Zhao BQ, et al. Inflammation induces hemorrhage in thrombocytopenia. Blood (2008) 111(10):4958-64. doi:10.1182/blood-2007-11-123620

33. Kedzierska M, Czernek U, Szydlowska-Pazera K, Potemski P, Piekarski J, Jeziorski A, et al. The changes of blood platelet activation in breast cancer patients before surgery, after surgery, and in various phases of the chemotherapy. Platelets (2013) 24(6):462-8. doi:10.3109/09537104.2012. 711866

34. Holmes CE, Levis JE, Schneider DJ, Bambace NM, Sharma D, Lal I, et al. Platelet phenotype changes associated with breast cancer and its treatment. Platelets (2016) 27(7):703-11. doi:10.3109/09537104.2016.1171302

35. Palumbo JS, Talmage KE, Massari JV, La Jeunesse CM, Flick MJ, Kombrinck KW, et al. Platelets and fibrin(ogen) increase metastatic potential by impeding natural killer cell-mediated elimination of tumor cells. Blood (2005) 105(1):178-85. doi:10.1182/blood-2004-06-2272

36. Nieswandt B, Hafner M, Echtenacher B, Männel DN. Lysis of tumor cells by natural killer cells in mice is impeded by platelets. Cancer Res (1999) 59(6):1295-300.

37. Borsig L, Wong R, Feramisco J, Nadeau DR, Varki NM, Varki A. Heparin and cancer revisited: mechanistic connections involving platelets,
P-selectin, carcinoma mucins, and tumor metastasis. Proc Natl Acad Sci U S A (2001) 98(6):3352-7. doi:10.1073/pnas.061615598

38. Kopp HG, Placke T, Salih HR. Platelet-derived transforming growth factor-beta down-regulates NKG2D thereby inhibiting natural killer cell antitumor reactivity. Cancer Res (2009) 69(19):7775-83. doi:10.1158/00085472.CAN-09-2123

39. Labelle M, Begum S, Hynes RO. Platelets guide the formation of early metastatic niches. Proc Natl Acad Sci U S A (2014) 111(30):E3053-61. doi:10.1073/ pnas. 1411082111

40. Schumacher D, Strilic B, Sivaraj KK, Wettschureck N, Offermanns S. Platelet-derived nucleotides promote tumor-cell transendothelial migration and metastasis via P2Y2 receptor. Cancer Cell (2013) 24(1):130-7. doi:10.1016/i.ccr.2013.05.008

41. Di Vito C, Navone SE, Marfia G, Abdel Hadi L, Mancuso ME, Pecci A, et al. Platelets from glioblastoma patients promote angiogenesis of tumor endothelial cells and exhibit increased VEGF content and release. Platelets (2016) 29:1-10. doi:10.1080/09537104.2016.1247208

42. Labelle M, Begum S, Richard O. Hynes: direct signaling between platelets and cancer cells induces an epithelial-mesenchymal-like transition and promotes metastasis. Cancer Cell (2011) 20(5):576-90. doi:10.1016/j.ccr. 2011.09.009

43. Baj-Krzyworzeka M, Majka M, Pratico D, Ratajczak J, Vilaire G, Kijowski J, et al. Platelet-derived microparticles stimulate proliferation, survival, adhesion, and chemotaxis of hematopoietic cells. Exp Hematol (2002) 30(5):450-9. doi:10.1016/S0301-472X(02)00791-9

44. Dashevsky O, Varon D, Brill A. Platelet-derived microparticles promote invasiveness of prostate cancer cells via upregulation of MMP-2 production. Int J Cancer (2009) 124(8):1773-7. doi:10.1002/ijc.24016

45. Ma L, Perini R, McKnight W, Dicay M, Klein A, Hollenberg MD, et al. Proteinase-activated receptors 1 and 4 counter-regulate endostatin and VEGF release from human platelets. Proc Natl Acad Sci U S A (2005) 102(1):216-20. doi:10.1073/pnas.0406682102

46. Hwang SG, Kim KM, Cheong JH, Kim HI, An JY, Hyung WJ, et al. Impact of pretreatment thrombocytosis on blood-borne metastasis and prognosis of gastric cancer. Eur J Surg Oncol (2012) 38(7):562-7. doi:10.1016/j. ejso.2012.04.009

47. Maráz A, Furák J, Varga Z, Kahán Z, Tiszlavicz L, Hideghéty K. Thrombocytosis has a negative prognostic value in lung cancer. Anticancer Res (2013) 33(4):1725-9.

48. Taucher S, Salat A, Gnant M, Kwasny W, Mlineritsch B, Menzel RC, et al. Study: impact of pretreatment thrombocytosis on survival in primary breast cancer. Thromb Haemost (2003) 89(6):1098-106. doi:10.1267/ THRO03061098

49. Erdemir F, Kilciler M, Bedir S, Ozgok Y, Coban H, Erten K. Clinical significance of platelet count in patients with renal cell carcinoma. Urol Int (2007) 79(2):111-6. doi:10.1159/000106322

50. Brown KM, Domin C, Aranha GV, Yong S, Shoup M. Increased preoperative platelet count is associated with decreased survival after resection for adenocarcinoma of the pancreas. Am J Surg (2005) 189(3):278-82. doi:10.1016/j.amjsurg.2004.11.014

51. van Es N, Sturk A, Middeldorp S, Nieuwland R. Effects of cancer on platelets. Semin Oncol (2014) 41(3):311-8. doi:10.1053/j.seminoncol.2014.04.015

52. Medina C, Jurasz P, Santos-Martinez MJ, Jeong SS, Mitsky T, Chen R, et al. Platelet aggregation-induced by caco- 2 cells: regulation by matrix metalloproteinase-2 and adenosine diphosphate. JPharmacol Exp Ther (2006) 317(2):739-45. doi:10.1124/jpet.105.098384

53. Pearlstein E, Ambrogio C, Gasic G, Karpatkin S. Inhibition of the platelet-aggregating activity of two human adenocarcinomas of the colon and an anaplastic murine tumor with a specific thrombin inhibitor, dansylarginine N-(3-ethyl-1,5-pentanediyl)amide. Cancer Res (1981) 41(11 Pt 1): 4535-9.

54. Schacht V, Dadras SS, Johnson LA, Jackson DG, Hong YK, Detmar M. Up-regulation of the lymphatic marker podoplanin, a mucin-type transmembrane glycoprotein, in human squamous cell carcinomas and germ cell tumors. Am J Pathol (2005) 166(3):913-21. doi:10.1016/S0002-9440(10) 62311-5

55. Suzuki-Inoue K. Essential in vivo roles of the platelet activation receptor CLEC-2 in tumour metastasis, lymphangiogenesis and thrombus formation. J Biochem (2011) 150(2):127-32. doi:10.1093/jb/mvr079 
56. Fujita N, Takagi S. The impact of Aggrus/podoplanin on platelet aggregation and tumour metastasis. J Biochem (2012) 152(5):407-13. doi:10.1093/jb/ mvs 108

57. Honn K, Cavanaugh P, Evens C, Taylor J, Sloane B. Tumor cell-platelet aggregation: induced by cathepsin B-like proteinase and inhibited by prostacyclin. Science (1982) 217(4559):540-2. doi:10.1126/science.7046053

58. Sabin RJ, Anderson RM. Cellular senescence - its role in cancer and the response to ionizing radiation. Genome Integr (2011) 2(1):1-9. doi:10.1186/ 2041-9414-2-7

59. Hager K, Setzer J, Vogl T, Voit J, Platt D. Blood coagulation factors in the elderly. Arch Gerontol Geriatr (1989) 9(3):277-82. doi:10.1016/0167-4943(89) 90047-2

60. Sagripanti A, Carpi A. Natural anticoagulants, aging, and thromboembolism. Exp Gerontol (1998) 33(7-8):891-6. doi:10.1016/S0531-5565(98) 00047-3

61. Kannel WB, Wolf PA, Castelli WP, D’Agostino RB. Fibrinogen and risk of cardiovascular disease: the framingham study. JAMA (1987) 258(9):1183-6. doi:10.1001/jama.1987.03400090067035

62. Wilhelmsen L, Svärdsudd K, Korsan-Bengtsen K, Larsson B, Welin L, Tibblin G. Fibrinogen as a risk factor for stroke and myocardial infarction. N Engl J Med (1984) 311(8):501-5. doi:10.1056/NEJM198408233110804

63. Ershler WB. Interleukin-6: a cytokine for gerontolgists. J Am Geriatr Soc (1993) 41(2):176-81. doi:10.1111/j.1532-5415.1993.tb02054.x

64. Gleerup $\mathrm{G}$, Winther $\mathrm{K}$. The effect of ageing on platelet function and fibrinolytic activity. Angiology (1995) 46(8):715-8. doi:10.1177/000331979504600810

65. Zahavi J, Jones NAG, Leyton J, Dubiel M, Kakkar VV. Enhanced in vivo platelet "release reaction" in old healthy individuals. Thromb Res (1980) 17(3):329-36. doi:10.1016/0049-3848(80)90067-5

66. Kasjanovová D, Baláẑ V. Age-related changes in human platelet function in vitro. Mech Ageing Dev (1986) 37(2):175-82. doi:10.1016/0047-6374(86) 90074-6

67. Celermajer DS, Sorensen KE, Bull C, Robinson J, Deanfield JE. Endotheliumdependent dilation in the systemic arteries of asymptomatic subjects relates to coronary risk factors and their interaction. J Am Coll Cardiol (1994) 24(6):1468-74. doi:10.1016/0735-1097(94)90141-4

68. Taddei S, Virdis A, Ghiadoni L, Salvetti G, Bernini G, Magagna A, et al. Age-related reduction of NO availability and oxidative stress in humans. Hypertension (2001) 38(2):274-9. doi:10.1161/01.hyp.38.2.274

69. López-Otín C, Blasco MA, Partridge L, Serrano M, Kroemer G. The hallmarks of aging. Cell (2013) 153(6):1194-217. doi:10.1016/j.cell.2013.05.039

70. Krishnamurthy J, Ramsey MR, Ligon KL, Torrice C, Koh A, Bonner-Weir S, et al. p16INK4a induces an age-dependent decline in islet regenerative potential. Nature (2006) 443(7110):453-7. doi:10.1038/ nature05092

71. Wang C, Jurk D, Maddick M, Nelson G, Martin-Ruiz C, Von Zglinicki T. DNA damage response and cellular senescence in tissues of aging mice. Aging Cell (2009) 8(3):311-23. doi:10.1111/j.1474-9726.2009.00481.x

72. Hayflick L. The limited in vitro lifetime of human diploid cell strains. Exp Cell Res (1965) 37:614-36. doi:10.1016/0014-4827(65)90211-9

73. Sherr CJ. Principles of tumor suppression. Cell (2004) 116(2):235-46. doi:10.1016/S0092-8674(03)01075-4

74. Krizhanovsky V, Yon M, Dickins RA, Hearn S, Simon J, Miething C, et al. Senescence of activated stellate cells limits liver fibrosis. Cell (2008) 134(4):657-67. doi:10.1016/j.cell.2008.06.049

75. Munoz-Espin D, Canamero M, Maraver A, Gomez-Lopez G, Contreras J, Murillo-Cuesta S, et al. Programmed cell senescence during mammalian embryonic development. Cell (2013) 155(5):1104-18. doi:10.1016/j.cell. 2013.10.019

76. Rajagopalan S, Long EO. Cellular senescence induced by CD158d reprograms natural killer cells to promote vascular remodeling. Proc Natl Acad Sci U S A (2012) 109(50):20596-601. doi:10.1073/pnas.1208248109

77. Storer M, Mas A, Robert-Moreno A, Pecoraro M, Ortells MC, Di Giacomo V, et al. Keyes: senescence is a developmental mechanism that contributes to embryonic growth and patterning. Cell (2013) 155(5):1119-30. doi:10.1016/j. cell.2013.10.041

78. Campisi J, d'Adda di Fagagna F. Cellular senescence: when bad things happen to good cells. Nat Rev Mol Cell Biol (2007) 8(9):729-40. doi:10.1038/ nrm 2233
79. Zhao H, Halicka HD, Traganos F, Jorgensen E, Darzynkiewicz Z. New biomarkers probing depth of cell senescence assessed by laser scanning cytometry. Cytometry A (2010) 77(11):999-1007. doi:10.1002/cyto.a. 20983

80. Gary RK, Kindell SM. Quantitative assay of senescence-associated betagalactosidase activity in mammalian cell extracts. Anal Biochem (2005) 343(2):329-34. doi:10.1016/j.ab.2005.06.003

81. Aird KM, Zhang R. Detection of senescence-associated heterochromatin foci (SAHF). Methods Mol Biol (2013) 965:185-96. doi:10.1007/ 978-1-62703-239-1_12

82. Narita M, Nunez S, Heard E, Narita M, Lin AW, Hearn SA, et al. $\mathrm{Rb}$-mediated heterochromatin formation and silencing of E2F target genes during cellular senescence. Cell (2003) 113(6):703-16. doi:10.1016/ S0092-8674(03)00401-X

83. Beausejour CM, Krtolica A, Galimi F, Narita M, Lowe SW, Yaswen P, et al. Reversal of human cellular senescence: roles of the p53 and p16 pathways. EMBO J (2003) 22(16):4212-22. doi:10.1093/emboj/cdg417

84. Purvis JE, Karhohs KW, Mock C, Batchelor E, Loewer A, Lahav G. p53 dynamics control cell fate. Science (2012) 336(6087):1440-4. doi:10.1126/ science. 1218351

85. Adams PD. Healing and hurting: molecular mechanisms, functions, and pathologies of cellular senescence. Mol Cell (2009) 36(1):2-14. doi:10.1016/j. molcel.2009.09.021

86. Bazarov AV, Lee WJ, Bazarov I, Bosire M, Hines WC, Stankovich B, et al. The specific role of pRb in p16 (INK4A) - mediated arrest of normal and malignant human breast cells. Cell Cycle (2012) 11(5):1008-13. doi:10.4161/ cc.11.5.19492

87. Sharpless NE, Sherr CJ. Forging a signature of in vivo senescence. Nat Rev Cancer (2015) 15(7):397-408. doi:10.1038/nrc3960

88. Jun JI, Lau LF. Cellular senescence controls fibrosis in wound healing. Aging (Albany NY) (2010) 2(9):627-31. doi:10.18632/aging.100201

89. Baker DJ, Perez-Terzic C, Jin F, Pitel KS, Niederlander NJ, Jeganathan K, et al. Opposing roles for p16Ink4a and p19Arf in senescence and ageing caused by BubR1 insufficiency. Nat Cell Biol (2008) 10(7):825-36. doi: $10.1038 /$ ncb 1744

90. Collado M, Serrano M. Senescence in tumours: evidence from mice and humans. Nat Rev Cancer (2010) 10(1):51-7. doi:10.1038/nrc2772

91. Chien Y, Scuoppo C, Wang X, Fang X, Balgley B, Bolden JE, et al. Control of the senescence-associated secretory phenotype by NF-kappaB promotes senescence and enhances chemosensitivity. Genes Dev (2011) 25(20): 2125-36. doi:10.1101/gad.17276711

92. Tchkonia T, Zhu Y, van Deursen J, Campisi J, Kirkland JL. Cellular senescence and the senescent secretory phenotype: therapeutic opportunities. JClin Invest (2013) 123(3):966-72. doi:10.1172/JCI64098

93. Coppe JP, Desprez PY, Krtolica A, Campisi J. The senescence-associated secretory phenotype: the dark side of tumor suppression. Annu Rev Pathol (2010) 5:99-118. doi:10.1146/annurev-pathol-121808-102144

94. Parrinello S, Coppe JP, Krtolica A, Campisi J. Stromal-epithelial interactions in aging and cancer: senescent fibroblasts alter epithelial cell differentiation. J Cell Sci (2005) 118(Pt 3):485-96. doi:10.1242/jcs.01635

95. Rodier F, Campisi J. Four faces of cellular senescence. J Cell Biol (2011) 192(4):547-56. doi:10.1083/jcb.201009094

96. Salama R, Sadaie M, Hoare M, Narita M. Cellular senescence and its effector programs. Genes Dev (2014) 28(2):99-114. doi:10.1101/gad.235184.113

97. Franceschi C, Campisi J. Chronic inflammation (inflammaging) and its potential contribution to age-associated diseases. J Gerontol A Biol Sci Med Sci (2014) 69(Suppl 1):S4-9. doi:10.1093/gerona/glu057

98. Rodier F, Coppe J-P, Patil CK, Hoeijmakers WAM, Munoz DP, Raza SR, et al. Persistent DNA damage signalling triggers senescenceassociated inflammatory cytokine secretion. Nat Cell Biol (2009) 11(8): 973-9. doi:10.1038/ncb1909

99. Shelton DN, Chang E, Whittier PS, Choi D, Funk WD. Microarray analysis of replicative senescence. Curr Biol (1999) 9(17):939-45. doi:10.1016/S09609822(99)80420-5

100. Pribluda A, Elyada E, Wiener Z, Hamza H, Goldstein RE, Biton M, et al. A senescence-inflammatory switch from cancer-inhibitory to cancerpromoting mechanism. Cancer Cell (2013) 24(2):242-56. doi:10.1016/j. ccr.2013.06.005 
101. Bernal GM, Wahlstrom JS, Crawley CD, Cahill KE, Pytel P, Liang H, et al. Loss of Nfkb1 leads to early onset aging. Aging (Albany NY) (2014) 6(11):931-42. doi:10.18632/aging.100702

102. Kuilman T, Michaloglou C, Vredeveld LC, Douma S, van Doorn R, Desmet CJ, et al. Oncogene-induced senescence relayed by an interleukindependent inflammatory network. Cell (2008) 133(6):1019-31. doi:10.1016/j. cell.2008.03.039

103. Orjalo AV, Bhaumik D, Gengler BK, Scott GK, Campisi J. Cell surfacebound IL-1 $\alpha$ is an upstream regulator of the senescence-associated IL-6/ IL-8 cytokine network. Proc Natl Acad Sci U S A (2009) 106(40):17031-6. doi:10.1073/pnas.0905299106

104. Lasry A, Ben-Neriah Y. Senescence-associated inflammatory responses: aging and cancer perspectives. Trends Immunol (2015) 36(4):217-28. doi:10.1016/j.it.2015.02.009

105. Acosta JC, Banito A, Wuestefeld T, Georgilis A, Janich P, Morton JP, et al. A complex secretory program orchestrated by the inflammasome controls paracrine senescence. Nat Cell Biol (2013) 15(8):978-90. doi:10.1038/ ncb2784

106. Lujambio A. To clear, or not to clear (senescent cells)? That is the question. Bioessays (2016) 38(Suppl 1):S56-64. doi:10.1002/bies.201670910

107. Xue W, Zender L, Miething C, Dickins RA, Hernando E, Krizhanovsky V, et al. Senescence and tumour clearance is triggered by p53 restoration in murine liver carcinomas. Nature (2007) 445(7128):656-60. doi:10.1038/ nature 05529

108. Watanabe S, Kawamoto S, Ohtani N, Hara E. Impact of senescenceassociated secretory phenotype and its potential as a therapeutic target for senescence-associated diseases. Cancer Sci (2017) 108(4):563-9. doi:10.1111/cas.13184

109. Lujambio A, Akkari L, Simon J, Grace D, Tschaharganeh DF, Bolden JE, et al. Non-cell-autonomous tumor suppression by p53. Cell (2013) 153 (2):449-60. doi:10.1016/j.cell.2013.03.020

110. Iannello A, Thompson TW, Ardolino M, Lowe SW, Raulet DH. p53dependent chemokine production by senescent tumor cells supports NKG2D-dependent tumor elimination by natural killer cells. J Exp Med (2013) 210(10):2057-69. doi:10.1084/jem.20130783

111. Demaria M, O'Leary MN, Chang JH, Shao LJ, Liu S, Alimirah F, et al. Cellular senescence promotes adverse effects of chemotherapy and cancer relapse. Cancer Discov (2017) 7(2):165-76. doi:10.1158/2159-8290.CD16-0241

112. Kang TW, Yevsa T, Woller N, Hoenicke L, Wuestefeld T, Dauch D, et al. Senescence surveillance of pre-malignant hepatocytes limits liver cancer development. Nature (2011) 479(7374):547-51. doi:10.1038/nature10599

113. Liu Y, Hawkins OE, Su YJ, Vilgelm AE, Sobolik T, Thu YM, et al. Targeting aurora kinases limits tumour growth through DNA damagemediated senescence and blockade of NF- $\mathrm{\kappa B}$ impairs this drug-induced senescence. EMBO Mol Med (2013) 5(1):149-66. doi:10.1002/emmm. 201201378

114. Bavik C, Coleman I, Dean JP, Knudsen B, Plymate S, Nelson PS. The gene expression program of prostate fibroblast senescence modulates neoplastic epithelial cell proliferation through paracrine mechanisms. Cancer Res (2006) 66(2):794-802. doi:10.1158/0008-5472.CAN-05-1716

115. Dilley TK, Bowden GT, Chen QM. Novel mechanisms of sublethal oxidant toxicity: induction of premature senescence in human fibroblasts confers tumor promoter activity. Exp Cell Res (2003) 290(1):38-48. doi:10.1016/ S0014-4827(03)00308-2

116. Krtolica A, Parrinello S, Lockett S, Desprez P-Y, Campisi J. Senescent fibroblasts promote epithelial cell growth and tumorigenesis: a link between cancer and aging. Proc Natl Acad Sci U S A (2001) 98(21):12072-7. doi:10.1073/pnas.211053698

117. Ohuchida K, Mizumoto K, Murakami M, Qian L-W, Sato N, Nagai E, et al. Radiation to stromal fibroblasts increases invasiveness of pancreatic cancer cells through tumor-stromal interactions. Cancer Res (2004) 64(9):3215-22. doi:10.1158/0008-5472.can-03-2464

118. Coppe J-P, Boysen M, Sun CH, Wong BJF, Kang MK, Park N-H, et al. A role for fibroblasts in mediating the effects of tobacco-induced epithelial cell growth and invasion. Mol Cancer Res (2008) 6(7):1085-98. doi:10.1158/ 1541-7786.mcr-08-0062
119. Bhatia B, Multani AS, Patrawala L, Chen X, Calhoun-Davis T, Zhou JJ, et al. Evidence that senescent human prostate epithelial cells enhance tumorigenicity: cell fusion as a potential mechanism and inhibition by p16INK4a and hTERT. Int J Cancer (2008) 122(7):1483-95. doi:10.1002/ijc.23222

120. Nickoloff BJ, Lingen MW, Chang BD, Shen M, Swift M, Curry J, et al. Tumor suppressor maspin is up-regulated during keratinocyte senescence, exerting a paracrine antiangiogenic activity. Cancer Res (2004) 64(9):2956-61. doi:10.1158/0008-5472.Can-03-2388

121. Wajapeyee N, Serra RW, Zhu X, Mahalingam M, Green MR. Oncogenic BRAF induces senescence and apoptosis through pathways mediated by the secreted protein IGFBP7. Cell (2008) 132(3):363-74. doi:10.1016/j.cell. 2007.12.032

122. Ferrucci L, Corsi A, Lauretani F, Bandinelli S, Bartali B, Taub DD, et al. The origins of age-related proinflammatory state. Blood (2005) 105(6): 2294-9. doi:10.1182/blood-2004-07-2599

123. Oleksowicz L, Mrowiec Z, Zuckerman D, Isaacs R, Dutcher J, Puszkin E. Platelet activation induced by interleukin-6: evidence for a mechanism involving arachidonic acid metabolism. Thromb Haemost (1994) 72(2):302-8

124. Davalos AR, Coppe J-P, Campisi J, Desprez P-Y. Senescent cells as a source of inflammatory factors for tumor progression. Cancer Metastasis Rev (2010) 29(2):273-83. doi:10.1007/s10555-010-9220-9

125. Comi P, Chiaramonte R, Maier JA. Senescence-dependent regulation of type 1 plasminogen activator inhibitor in human vascular endothelial cells. Exp Cell Res (1995) 219(1):304-8. doi:10.1006/excr.1995.1232

126. Markiewicz M, Richard E, Marks N, Ludwicka-Bradley A. Impact of endothelial microparticles on coagulation, inflammation, and angiogenesis in age-related vascular diseases. J Aging Res (2013) 2013:734509. doi:10.1155/ 2013/734509

127. Wang Y, Reheman A, Spring CM, Kalantari J, Marshall AH, Wolberg AS, et al. Plasma fibronectin supports hemostasis and regulates thrombosis. J Clin Invest (2014) 124(10):4281-93. doi:10.1172/JCI74630

128. Dams-Kozlowska H, Kwiatkowska-Borowczyk E, Gryska K, Mackiewicz A. Designer cytokine hyper interleukin 11 (H11) is a megakaryopoietic factor. Int J Med Sci (2013) 10(9):1157-65. doi:10.7150/ijms.5638

129. Yamamoto K, Takeshita K, Saito H. Plasminogen activator inhibitor-1 in aging Semin Thromb Hemost (2014) 40(6):652-9. doi:10.1055/s-0034-1384635

130. Jurasz P, Sawicki G, Duszyk M, Sawicka J, Miranda C, Mayers I, et al. Matrix metalloproteinase 2 in tumor cell-induced platelet aggregation: regulation by nitric oxide. Cancer Res (2001) 61(1):376-82.

131. Wang Y, Carrim N, Ni H. Fibronectin orchestrates thrombosis and hemostasis. Oncotarget (2015) 6(23):19350-1. doi:10.18632/oncotarget.5097

132. Ryu T, Nishimura S, Miura H, Yamada H, Morita H, Miyazaki H, et al. Thrombopoietin-producing hepatocellular carcinoma. Intern Med (2003) 42(8):730-4. doi:10.2169/internalmedicine.42.730

133. Fuchs TA, Brill A, Duerschmied D, Schatzberg D, Monestier M, Myers DD Jr, et al. Extracellular DNA traps promote thrombosis. Proc Natl Acad Sci U S A (2010) 107(36):15880-5. doi:10.1073/pnas.1005743107

134. Seizer P, May AE. Platelets and matrix metalloproteinases. Thromb Haemost (2013) 110(5):903-9. doi:10.1160/TH13-02-0113

135. Campisi J. Aging, cellular senescence, and cancer. Annu Rev Physiol (2013) 75:685-705. doi:10.1146/annurev-physiol-030212-183653

136. Badimon L, Padro T, Vilahur G. Atherosclerosis, platelets and thrombosis in acute ischaemic heart disease. Eur Heart J Acute Cardiovasc Care (2012) 1(1):60-74. doi:10.1177/2048872612441582

Conflict of Interest Statement: The authors declare that the research was conducted in the absence of any commercial or financial relationships that could be construed as a potential conflict of interest.

Copyright (c) 2017 Valenzuela, Quintanilla, Moore-Carrasco and Brown. This is an open-access article distributed under the terms of the Creative Commons Attribution License (CC BY). The use, distribution or reproduction in other forums is permitted, provided the original author(s) or licensor are credited and that the original publication in this journal is cited, in accordance with accepted academic practice. No use, distribution or reproduction is permitted which does not comply with these terms. 